Slavica

bruxellensia

\section{Slavica bruxellensia}

Revue polyphonique de littérature, culture et histoire

slaves

$3 \mid 2009$

Pensée des hommes

\title{
Tadeusz Różewicz, Kup kota w worku (work in progress)
}

\section{Alexandra Dufour}

\section{OpenEdition}

\section{Journals}

Édition électronique

URL : http://journals.openedition.org/slavica/221

DOI : 10.4000/slavica.221

ISSN : 2034-6395

\section{Éditeur}

Université libre de Bruxelles - ULB

\section{Édition imprimée}

Pagination : 105-106

ISSN : 2031-7654

Référence électronique

Alexandra Dufour, «Tadeusz Różewicz, Kup kota w worku (work in progress) », Slavica bruxellensia [En ligne], 3 | 2009, mis en ligne le 09 mai 2012, consulté le 22 septembre 2020. URL : http:// journals.openedition.org/slavica/221 ; DOI : https://doi.org/10.4000/slavica.221

Ce document a été généré automatiquement le 22 septembre 2020

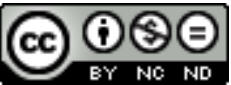

Les contenus de Slavica bruxellensia sont mis à disposition selon les termes de la Licence Creative Commons Attribution - Pas d'Utilisation Commerciale - Pas de Modification 3.0 France. 


\section{Tadeusz Różewicz, Kup kota w worku (work in progress)}

Alexandra Dufour

RÉFÉRENCE

Tadeusz Różewicz, Kup kota w worku (work in progress), Wrocław, Biuro Literackie, 2008, $106 \mathrm{p}$. 
1 Avec ce nouvel ouvrage, Tadeusz Różewicz surprend le lecteur et l'emmène dans des endroits inhabituels afin de lui faire découvrir sa perception du monde.

2 L'auteur enfile ses vielles chaussures et part se promener dans la réalité. Il observe, écoute et lit tout ce qui se passe autour de lui. Il regarde la réalité droit dans les yeux et nous la commente à travers le prisme d'une ironie piquante et d'un humour grinçant.

La force de ce recueil tient notamment à sa composition. La prose, la poésie, les petites pièces de théâtre agrémentées de dessins humoristiques et de notes manuscrites constituent un véritable patchwork bigarré.

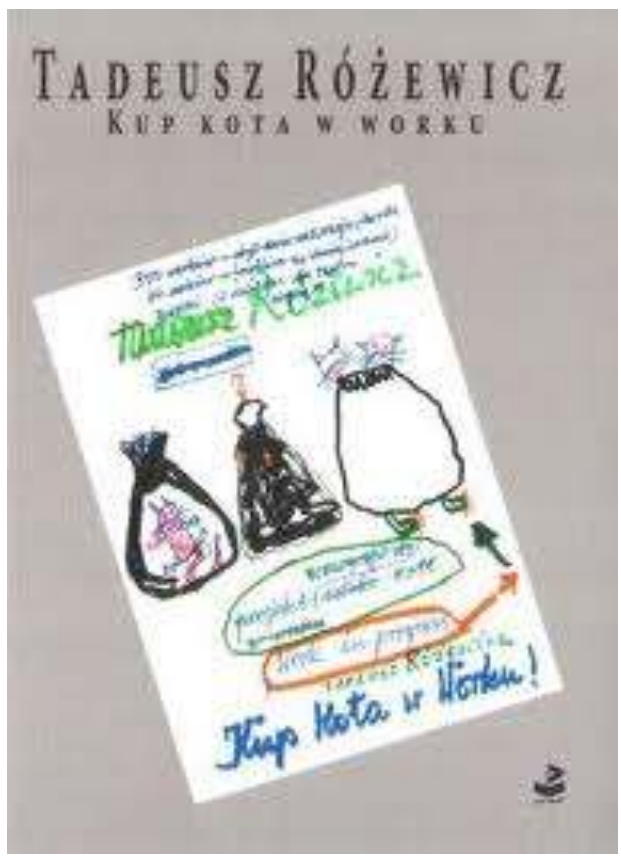

4 Dans Kup kota $w$ worku (Achète un chat dans un sac), l'écrivain n'hésite pas à pointer du doigt les travers de notre société contemporaine. Il s'attaque à la culture de masse, dont le jeune Harry Potter fait bien souvent les frais, à la « globalisation des sms », à la télévision et à l'internet.

5 Par le pastiche et les jeux de mots, il s'en prend également à la jeune génération dégénérée pour laquelle le langage a cessé d'être communicatif et l'orthographe et la grammaire se pratiquent selon des règles aléatoires. Sur le ton du sarcasme et avec une véritable verve linguistique, il s'amuse à parodier la langue polonaise qui a été prise en otage par les américanismes et les vulgarismes. Autant dire que personne n'échappe à l'humour tranchant du poète, que ce soit les « Don Juan du chat », les journalistes, les jeunes, les starlettes, les copywriters, les bloggeurs, les politiciens ou les artistes.

Różewicz n'a certes jamais été un grand optimiste, cependant il a toujours conservé son sens de l'humour, un humour qui se veut tantôt émouvant et raffiné, tantôt acéré et sans pitié.

7 C'est sans doute l'un des volumes les plus singuliers et les plus étonnants de l'auteur. Le lecteur aurait tort de ne pas prendre l'invitation de Różewicz au sérieux : enfiler ses vieilles chaussures à son tour et continuer à rêver un peu plus.

\section{INDEX}

Index géographique : Pologne

Index chronologique : XXe siècle, XXIe siècle

Mots-clés : littérature polonaise 


\section{AUTEURS}

\section{ALEXANDRA DUFOUR}

Étudiante à l'Université Libre de Bruxelles en Langues et Littératures modernes, orientation slaves 